\title{
Association between clinical features and YMDD mutations in patients with chronic hepatitis B following lamivudine therapy
}

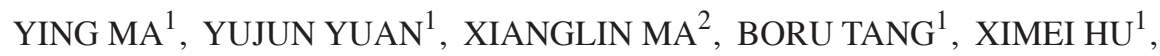 \\ JUAN FENG ${ }^{1}$, LI TIAN ${ }^{3}$, YAOHUA JI ${ }^{4}$ and XIAOGUANG DOU ${ }^{5}$ \\ ${ }^{1}$ Department of Neurology, Shengjing Hospital of China Medical University, Shenyang, Liaoning 110817; \\ ${ }^{2}$ Department of General Surgery, The Third People's Hospital of Wafangdian, Wafangdian, Liaoning 116300; \\ Departments of ${ }^{3}$ Geriatrics, ${ }^{4}$ Virus and ${ }^{5}$ Infectious Disease, Shengjing Hospital of China Medical University, \\ Shenyang, Liaoning 110817, P.R. China
}

Received March 11, 2015; Accepted April 19, 2016

DOI: $10.3892 / \mathrm{etm} .2016 .3365$

\begin{abstract}
The aim of the present study was to investigate the correlation between feature and genotype with regard to the tyrosine-methionine-aspartate-aspartate (YMDD) mutation in chronic hepatitis B patients after lamivudine (LAM) therapy. A total of 30 patients with chronic hepatitis B were recruited, who underwent one year of LAM therapy. The patients' alanine aminotransferase (ALT) level and hepatitis B envelope antigen ( $\mathrm{HBeAg})$ seroconversion were evaluated, hepatitis B virus (HBV) DNA was genotyped using a new genotyping method and YMDD mutations were analyzed prior to treatment and at 6 and 12 months after LAM treatment. Furthermore, the secondary protein structure of the HBV DNA polymerase gene (P gene) was analyzed. Following treatment, the results suggested that LAM therapy improved ALT normalization. There was no correlation between clinical effects and ALT level before treatment. After 12 months treatment, the rate of $\mathrm{HBeAg}$ loss increased and the rate of $\mathrm{HBeAg}$ seroconversion decreased linearly with the rise of baseline ALT level. While ALT normalization and $\mathrm{HBeAg}$ seroconversion were highest in patients with $\mathrm{HBV}$ genotype $\mathrm{B}, \mathrm{HBeAg}$ loss and HBVDNA loss were highest in those with genotype $\mathrm{C}$. The effect was predominant in genotype D. No YMDD mutations were identified prior to 6 months of LAM therapy. The rate of YMDD mutations after 12 months LAM therapy was $12.12 \%$. Two patients with rtM204V + rtL180M belonged to genotype $\mathrm{C}$ and
\end{abstract}

Correspondence to: Mrs. Ying Ma, Department of Neurology, Shengjing Hospital of China Medical University, 36 Sanhao Street, Heping, Shenyang, Liaoning 110817, P.R. China

E-mail: mayingwfd@163.com

Professor Xiaoguang Dou, Department of Infectious Disease, Shengjing Hospital of China Medical University, 36 Sanhao Street, Heping, Shenyang, Liaoning 110817, P.R. China

E-mail: douxg@sj-hospital.org

Key words: chronic hepatitis B, lamivudine, YMDD mutation, genotype, secondary protein structure another patient with rtL180M alone belonged to genotype D. The turn of secondary protein structure of $\mathrm{P}$ gene changed to $\beta$ sheet when a rtM204V mutation occurred, and no change of secondary protein structure was associated with the rtL180M mutation. Thus, the present results indicate that one year of LAM therapy is able to improve ALT normalization. Long-term LAM therapy may induce YMDD mutation and drug resistance.

\section{Introduction}

Hepatitis B virus (HBV) remains a major cause of morbidity and mortality worldwide (1). It has been estimated that $\sim 350$ million individuals worldwide are chronically infected with HBV. A proportion of these patients will subsequently develop hepatic cirrhosis, so therapy to control active inflammation is important (1). The key to effective treatment is to inhibit the replication of HBV and prevent it from progressing to cirrhosis, hepatic failure and hepatic cell cancer (2-4). Lamivudine (LAM) is an antiviral agent, and large scale control studies have suggested that LAM is able to inhibit the replication of HBV DNA, enhance hepatitis B e-antigen loss and seroconversion and improve the normalization of alanine aminotransferase (ALT), thus leading to histological improvement (5-7). The tyrosine-methionine-aspartate-aspartate (YMDD) motif of HBV is the binding site of LAM (8). When LAM is combined with the YMDD motif, LAM is able to inhibit the activation of polymerase, even in viral replication (9). However, long-term LAM therapy may induce HBV DNA polymerase (P gene) mutations and LAM resistance (8-13). The HBV polymerase is functionally and structurally related to human immunodeficiency virus reverse transcriptases (14). HBV DNA polymerase performs reversed transcription and exhibits a highly conserved YMDD motif. This motif, which is localized in the polymerase structural region $\mathrm{C}$ area, is the combing and functioning site of Lamivudine (a nucleoside antiviral). Lamivudine-resistant HBV strains with YMDD mutations have been implemented in the failure of chronic hepatitis B treatment (15). It has been reported that the seminested PCR products of the DNA polymerase gene exhibit intergenotypic divergence of $\geq 4 \%$, which is in accordance 
with the HBV DNA S gene sequence, with the exception of genotypes A and G, B and G, and F and H (16). Only genotypes B, C, D, and A have been detected in China. Therefore, a fragment of HBV DNA polymerase gene can be used for genotyping hepatitis B in China (16). This genotyping method may also be used to predict antiviral therapeutic responses among HBV genotypes and the development of drug resistance due to mutations. It is a valuable tool for guiding the treatment of lamivudine-resistant HBV in the clinical setting (16).

Different YMDD mutations can occur in different genotypes during LAM therapy $(5,14-16)$, and the effect of the genotype on LAM therapy is different $(5,17,18)$. Therefore, the present study aimed to investigate the correlation between feature and genotype with regard to the YMDD mutation in chronic hepatitis B patients following LAM therapy. Clinical features and YMDD mutations were assessed in Chinese patients with chronic hepatitis B following lamivudine therapy using serological tests, genotype analysis and analysis of mutation and secondary protein structure of the $\mathrm{P}$ gene via an ABI sequencing system.

\section{Materials and methods}

Patients. A total of 33 patients with chronic hepatitis B (22 males and 11 females; mean age, 31.79 years) were enrolled in this study between July 2006 and June 2011. These patients received LAM therapy (orally, $100 \mathrm{mg} / \mathrm{day}$; GlaxoSmithKine Plc, Brentford, UK) for at least 12 months. All patients were born and living in Shenyang (China). Patients who had received interferon- $\alpha$ or other nucleotide analogs, or those co-infected with hepatitis $\mathrm{C}$, hepatitis $\mathrm{D}$ and human immunodeficiency virus were excluded from the study. This study was approved by the Institutional Ethics Committee for clinical study of Shengjing Hospital of China Medical University (Shenyang, China). The patients were enrolled after providing written consent. Serum samples were collected prior to treatment, and at 6 and 12 months after LAM therapy and were stored at $-70^{\circ} \mathrm{C}$ for further examination.

Serological tests. Serum ALT was measured using standard procedures. Hepatitis B surface antigen (HBsAg; SBJ-H0844; Nanjing Lihong Chemical Science \& Technology Co., Ltd., Nanjing, China), hepatitis B envelop antigen (HBeAg; GFD6511) and anti-HBe were detected using commercial enzyme immunoassay kits (both Qingdao Jisskang Biotechnology, Co., Ltd., Qingdao, China). HBsAg, anti-HBs and anti-HBc were purchased from Abbott Laboratories (Abbott Park, IL, USA). $\mathrm{HBeAg}$ and anti-HBe were acquired from Organon Teknika Corporation (Durham, NC, USA). HBV DNA was detected using semi-nested polymerase chain reaction (PCR), as previously described (16).

Analysis of genotype, mutation and secondary protein structure of the $P$ gene. All positive PCR products were sequenced by Shanghai GeneCore BioTechnologies Co., Ltd., (Shanghai, China) using an ABI sequencing system (Applied Biosystems; Thermo Fisher Scientific, Inc., Waltham, MA, USA). With the aid of DNASTAR software (DNASTAR, Inc., Madison, WI, USA), three primers were designed the sequence the HBV DNA polymerase gene (accession number, AF100309): HBV381 (nt381-402), HBV840 (nt840-861), and HBV801 (nt801-822). The following primers were synthesized by Takara Biotechnology Co., Ltd., (Dalian, China): 5'-TGCGGCGTTTTA TCATCTTCCT-3', 5'-GTTTAAATGTATACCCAAAGAC-3' and 5'-CAGCGGCATAAAGGGACTCAAG-3', respectively. Two pairs of semi-nested PCR primers (HBV381/HBV840 and HBV381/ HBV801) were utilized in the amplification reaction, whereas primer HBV381 was used in the sequencing reaction.

Briefly, HBV DNA was extracted from 55 serum samples obtained from infected patients. The fragment of the polymerase gene was amplified by semi-nested PCR with two rounds of amplification. The reaction volume was $50 \mu \mathrm{l}$. The first round of amplification was performed with an initial $5 \mathrm{~min}$ denaturing step at $94^{\circ} \mathrm{C}$, followed by 30 cycles of denaturing for $45 \mathrm{sec}$ at $94^{\circ} \mathrm{C}$, annealing for $30 \mathrm{sec}$ at $50^{\circ} \mathrm{C}$, and elongation for $90 \mathrm{sec}$ at $72^{\circ} \mathrm{C}$, with a final extension step $\left(10 \mathrm{~min}\right.$ at $\left.72^{\circ} \mathrm{C}\right)$ using primers HBV381 and HBV840. The second round of amplification was performed with an initial 5 min denaturing step at $94^{\circ} \mathrm{C}$, followed by 30 cycles of denaturing for $45 \mathrm{sec}$ at $94^{\circ} \mathrm{C}$, annealing for $30 \mathrm{sec}$ at $55^{\circ} \mathrm{C}$, and elongation for $60 \mathrm{sec}$ at $72^{\circ} \mathrm{C}$, with a final extension step $\left(10 \mathrm{~min}\right.$ at $\left.72^{\circ} \mathrm{C}\right)$ using primers HBV381 and HBV801. The reaction products of the semi-nested PCR were visualized on a $2 \%$ agarose gel stained with ethidium bromide. Semi-nested PCR reaction products were subjected to purification and sequencing using the HBV381 primer through a commercial company (Shanghai GeneCore Bio Technologies Co., Ltd., Shanghai, China) on an ABI sequencing system (Applied Biosystems; Thermo Fisher Scientific, Inc.).

Purification, sequencing reaction, precipitation and automatic sequencing were performed on the positive PCR products, using a Wizard ${ }^{\circledR}$ PCR Preps DNA purification system kit and an ABI PRISM BigDye ${ }^{\mathrm{TM}}$ Terminator cycle Sequencing Ready Reaction Kit [Promega (Beijing) Biotech Co., Ltd., Beijing, China], as previously described (16).

The reagent boxes for use in PCR course were purchased from Fuhua Biomedical Engineering Co., Ltd. (Shanghai, China). Reagent boxes for purification were purchased from Promega Corp., (Madison, WA, USA). Automatic sequencing was performed by Shanghai GeneCore BioTechnologies Co., Ltd., using an ABI sequencing system.

First, the eight standard full-length nucleotide sequences of HBV DNA were obtained from GenBank (http://www. ncbi.nlm.nih.gov/genbank/), including genotypes A (accession no. AY128092), B (AB073858), C (AF461359), D (AY090453), E (X75664), F (X75663), G (AF405706) and H (AY090460). Sequences of the fragment of the $\mathrm{P}$ gene ( 262 base pairs) were genotyped as described in previously by Ma et al (16). Then, the mutations and secondary protein structure of the $\mathrm{P}$ gene were analyzed by the CLUSTAL V method using DNASTAR 5.0 software.

Statistical analysis. The $\chi^{2}$ test was used to compare variables between groups. $\mathrm{P}<0.05$ was considered statistically significant. All analyses were performed using the SPSS software, version 14.0 (SPSS, Inc., Chicago, IL, USA).

\section{Results}

Outcome of LAM therapy. The mean ALT values prior to treatment and at 6 and 12 months after treatment were $130.26 \mathrm{U} / 1$ 
Table I. Outcome of LAM therapy and association between ALT level at baseline and ALT level following treatment.

\begin{tabular}{lcccccc}
\hline ALT level & $\geq 5 \mathrm{x}$ ULN & $2-5 \mathrm{x}$ ULN & $1-2 \mathrm{x}$ ULN & $\leq 1$ ULN & P-value & Total \\
\hline $\begin{array}{l}\text { Baseline } \\
\text { Patients, } \mathrm{n}\end{array}$ & 7 & 11 & 13 & 2 & - & 33 \\
HBeAg+, $\mathrm{n}$ & $6 / 7$ & $9 / 11$ & $12 / 13$ & $2 / 2$ & - & $29 / 33$ \\
6 months, $\mathrm{n}(\%)$ & & & & & \\
$\quad$ ALT normalization & $7 / 7(100)$ & $9 / 11(81.82)$ & $12 / 13(92.31)$ & $2 / 2(100.00)$ & 0.566 & $30 / 33(90.91)$ \\
HBV DNA loss & $2 / 7(28.57)$ & $3 / 11(27.27)$ & $6 / 13(46.15)$ & $0 / 2(0)$ & 0.529 & $11 / 33(33.33)$ \\
12 months, $\mathrm{n}(\%)$ & & & & & & \\
ALT normalization & $6 / 7(85.71)$ & $10 / 11(90.91)$ & $10 / 13(76.92)$ & $2 / 2(100.00)$ & 0.727 & $28 / 33(84.85)$ \\
HBV DNA loss & $2 / 7(28.57)$ & $4 / 11(36.36)$ & $5 / 13(38.46)$ & $0 / 2(0)$ & 0.736 & $11 / 33(33.33)$ \\
YMDD mutation & $1 / 7$ & $2 / 11$ & $1 / 12$ & $0 / 2(0)$ & 0.235 & $4 / 33(12.12)$ \\
HBeAg loss & $6 / 6(100.00)$ & $7 / 9(77.78)$ & $7 / 12(58.33)$ & $1 / 2(50.00)$ & 0.250 & $21 / 29(72.41)$ \\
HBeAg seroconversion & $0 / 6(0)$ & $1 / 9(11.11)$ & $2 / 12(16.67)$ & $1 / 2(50.00)$ & 0.347 & $4 / 29(13.79)$ \\
\hline
\end{tabular}

Significance was calculated using the $\chi^{2}$ test. LAM, lamivudine; ALT, alanine aminotransferase; ULN, upper limit of normal; HBeAg, hepatitis B envelope antigen; HBV, hepatitis B virus; YMDD, tyrosine-methionine-aspartate-aspartate.

Table II. Genotype at baseline and the effect of genotype on the outcome of 12 months LAM therapy.

\begin{tabular}{lcccr}
\hline Parameter & Genotype B & Genotype C & Genotype D & P-value \\
\hline Genotype at baseline, n (\%) & $7(21.21)$ & $18(54.55)$ & $8(24.24)$ & $0.001 ;$ BC 0.005; CD 0.012 \\
ALT normalization, n (\%) & $7 / 7(100)$ & $14 / 18(77.78)$ & $7 / 8(87.50)$ & $0.369 ;$ BC 0.294; CD 1.0; BD 1.0 \\
HBeAg seroconversion, n (\%) & $1 / 6(16.67)$ & $2 / 15(13.33)$ & $1 / 8(12.50)$ & $0.973 ;$ BC 1.0; CD 1.0; BD 1.0 \\
HBeAg loss, n (\%) & $4 / 6(66.67)$ & $12 / 15(80)$ & $5 / 8(62.50)$ & $0.630 ;$ BC 0.598; CD 0.621; BD 1.0 \\
HBV DNA loss, n (\%) & $0 / 7(0)$ & $8 / 18(44.44)$ & $3 / 8(37.50)$ & $0.102 ;$ BC 0.032; CD 1.0; BD 0.070 \\
rtM204V, n & 0 & 2 & 0 & $0.412 ;$ BC 0.359; CD 0.326 \\
rtL180M, n & 0 & 3 & 1 & $0.518 ;$ BC 0.250; CD 0.786; BD 1.0 \\
\hline
\end{tabular}

$\mathrm{BC}$ represents the $\mathrm{P}$-value between genotype $\mathrm{B}$ and genotype $\mathrm{C}$. BD represents the P-value between genotype $\mathrm{B}$ and genotype $\mathrm{D}$. CD represents the P-value between genotype C and genotype D. LAM, lamivudine; ALT, alanine aminotransferase; HBeAg, hepatitis B envelope antigen; $\mathrm{HBV}$, hepatitis B virus.

(15-386 U/1), $27.48 \mathrm{U} / 1$ (8-64 U/1) and $27.06 \mathrm{U} / 1$ (8-110 U/1), respectively. No HBsAg loss or HBsAg seroconversion was detected following treatment. As shown in Table I, ALT normalization, HBV DNA loss and YMDD mutation after 6 months of treatment were 90.91, 33.33 and $0 \%$, respectively. ALT normalization, HBV DNA loss, YMDD mutation, $\mathrm{HBeAg}$ loss and HBeAg seroconversion [HBeAg (-), $\mathrm{HBeAb}$ $(+)$ after 12 months of treatment were 84.85, 33.33, 12.12, 72.41 and $13.79 \%$, respectively. Four groups of patients prior to treatment were classified according ALT level: $\geq 5 \mathrm{x}$ Upper limit of normal (ULN), 2-5x ULN, 1-2x ULN and $\leq 1 \mathrm{x}$ ULN. No significant differences were detected between these four groups in ALT level, and there were no differences in $\mathrm{HBeAg}$ loss and $\mathrm{HBeAg}$ seroconversion after 12 months of treatment between the four groups $(\mathrm{P}>0.05)$. However, following 12 months of treatment, the rate of HBeAg loss increased and the rate of $\mathrm{HBeAg}$ seroconversion decreased linearly (Table I).

Genotype and the association of genotype with the outcome after 12 months of LAM therapy. As shown in Table II, only genotypes B, C and D were detected in the 33 patients with chronic hepatitis B prior to treatment, with 7 cases of genotype B (21.21\%), 18 cases of genotype C $(54.55 \%)$ and 8 cases of genotype D $(24.24 \%)$, respectively. The difference of intergenotypic distribution in these three genotypes was significant $(\mathrm{P}=0.001)$ and the differences of distribution between genotype $\mathrm{C}$ and genotypes $\mathrm{B}$ or $\mathrm{D}$ were also statistically significant $(\mathrm{P}<0.05)$. Table II also shows the association between genotype and the outcome of 12 months of LAM therapy. ALT normalization and HBeAg seroconversion were highest in genotype $\mathrm{B}$ and $\mathrm{HBeAg}$ loss and HBV DNA loss were highest in genotype $C$. All therapeutic effects were most marked in genotype D, including ALT normalization, $\mathrm{HBeAg}$ loss, $\mathrm{HBeAg}$ seroconversion and HBV DNA loss; however, the difference of intergenotypic distribution in these three genotypes was not significant $(\mathrm{P}>0.05)$. Both rtM204V mutations (two patients) were detected in genotype C. A total of four rtL180M mutations appeared with three cases in genotype $\mathrm{C}$ (two mutations occur simultaneously with rtM204V), and one in genotype D (Table II). 


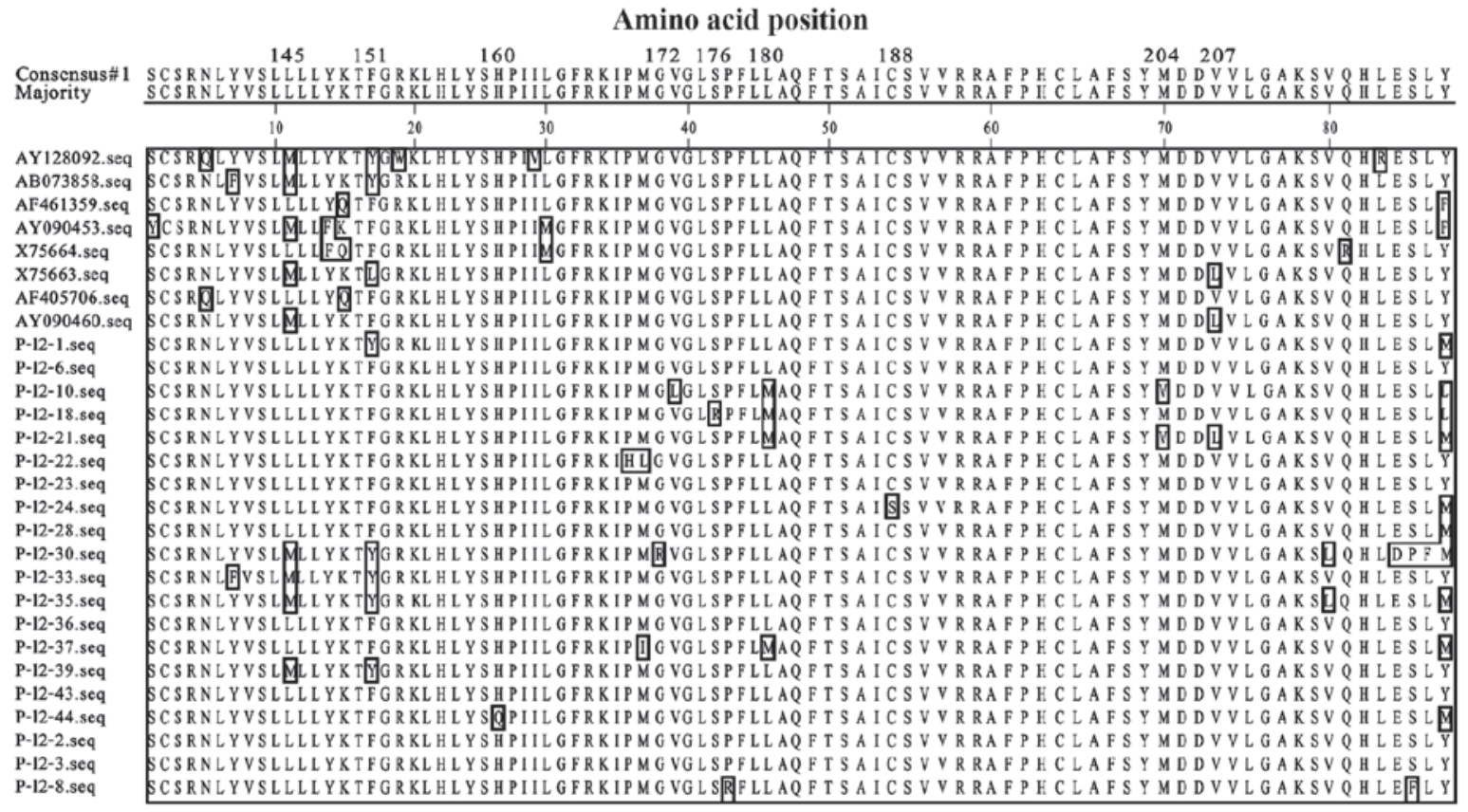

Figure 1. Alignment of amino acid sequence of hepatitis B virus DNA P gene encoded after 12 months of lamivudine therapy.

A
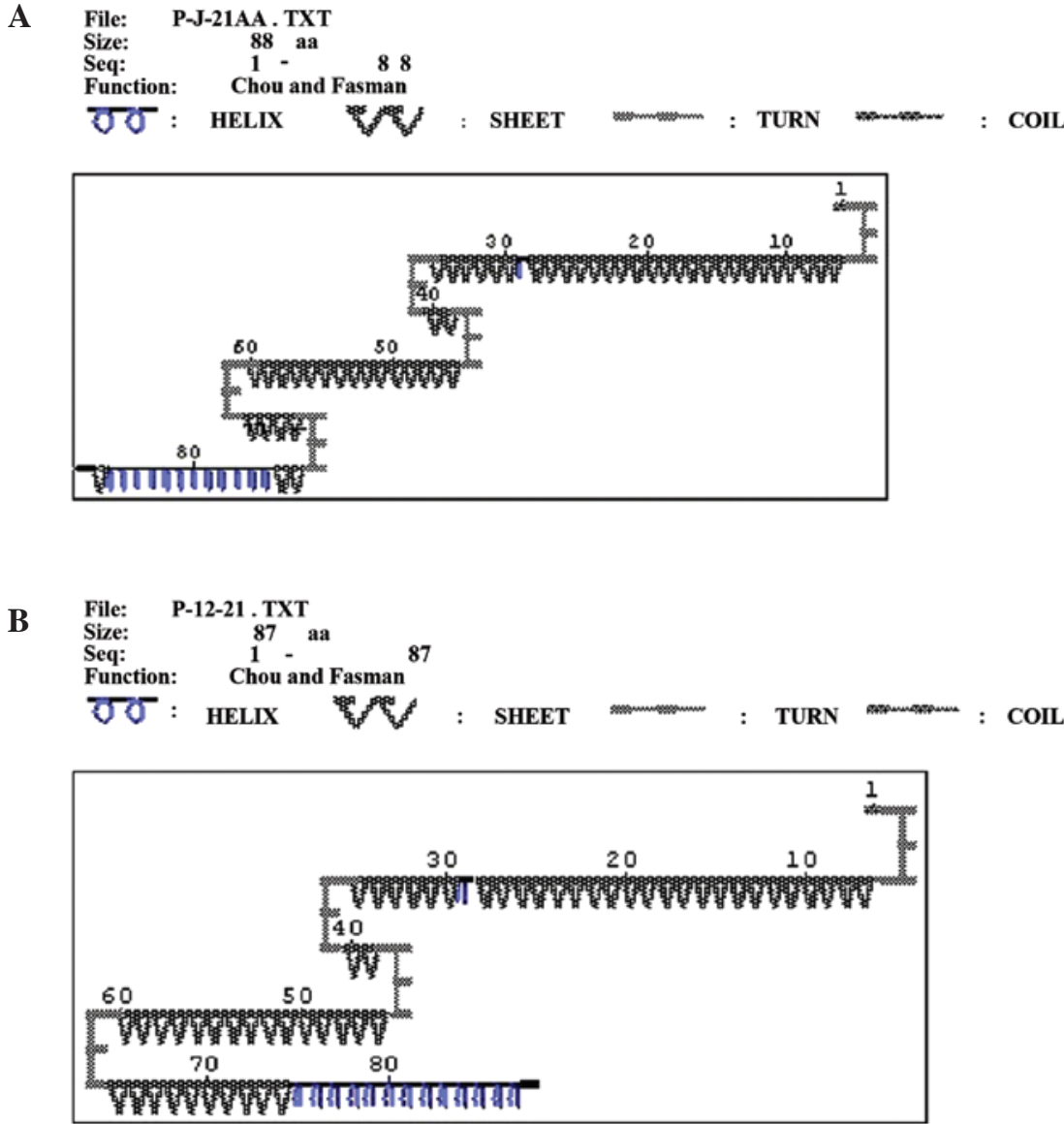

Figure 2. Secondary protein structure prediction of tyrosine-methionine-aspartate motif (A) before and (B) after the emergence of tyrosine-methionine-aspartate mutation 12 months after lamivudine therapy.

Mutations detected during LAM therapy and clinical symptoms. DNASTAR software analysis indicated no $\mathrm{rtM} 204 \mathrm{~V} / \mathrm{I}$ or rtL180M mutations prior to treatment or at 6 months after LAM therapy. As shown in Table I, the rate of YMDD mutations after 12 months LAM therapy was $12.12 \%$. Fig. 1 showed the alignment of amino acid sequences of HBV DNA 
P gene encoded after 12 months LAM therapy, which showed that there were two patients with rtM204V + rtL180M and two patients with rtL180M alone. Other mutations detected uncommon mutations were also listed in Fig. 1, such as rtV207 L (1 case), rtC188S (1 case), rtP177R (1 case), rtS176R (1 case), rtV173 L (1 case), rtG172R (1 case), rtH160Q (1 case), rtF151Y (5 cases) and rtL145 M (4 cases).

As shown in Tables I and II, the two patients with rtM204V + rtL180M belonged to genotype C, with ALT levels 2-5x ULN at baseline. One patient (HBeAg positive and abnormal ALT at baseline) was HBeAg positive, with ALT increasing and LAM resistance appearing after 12 months of LAM therapy. The other patient (HBeAg negative at baseline) was $\mathrm{HBeAg}$ negative, $\mathrm{HBeAb}$ negative, normal ALT and exhibited no drug resistance after 12 months of LAM therapy. The other two patients with rtL180M alone belonged to genotype C and D, respectively. No drug resistance appeared to develop following 12 months of LAM therapy (Fig. 1).

Secondary protein structure prediction of YMDD motif prior to and following the occurrence of mutations. Using DNASTAR software, the corresponding sequences were analyzed when rtM204V/I or rtL180M mutations did not appear at baseline and appeared after 12 months of LAM therapy. As shown in Fig. 2, the secondary protein structure prediction of YMDD motif prior to and following the emergence of rtM204V + rtL180M mutations, 69-72 amino acids (AA) incurred a rtM204V mutation, whereas 46 AA changed to rtL180M. When there was no mutation at baseline, the secondary protein structure of $46 \mathrm{AA}$ and 69-72 AA was $\beta$ turn (Fig. 2A). When mutations appeared, the $\beta$ turn of 69-72 AA changed to $\beta$ sheet; however, the $\beta$ turn of 46 AA and the remainder of the secondary structure did not change (Fig. 2B).

\section{Discussion}

The results of the present study indicate that one year of LAM therapy can improve ALT normalization. The rate of $\mathrm{HBeAg}$ seroconversion was $13.79 \%$, which is similar to the rate of reported after one year LAM therapy in Asia by Lai et al (10), and lower than the documented rate of Schalm et al (20) and Dienstag et al (21). Chien et al (22) suggested that ALT level at baseline could predict $\mathrm{HBeAg}$ seroconversion independently, as the rates of $\mathrm{HBeAg}$ seroconversion in patients with ALT $>5 x$ ULN, 2-5x ULN and <2x ULN before treatment were 64, 26 and $5 \%$, respectively. In the present study, the rate of $\mathrm{HBeAg}$ loss was consistent with previous findings $(23,24)$; however, the rate of $\mathrm{HBeAg}$ seroconversion was different, which may be associated with the small sample size. This study suggested that there were no significant differences among the genotypes in terms of improvement of ALT normalization, $\mathrm{HBeAg}$ seroconversion, $\mathrm{HBeAg}$ loss and HBV DNA loss during LAM treatment (Fig. 2).

Long-term LAM therapy may induce YMDD mutations and drug resistance, which would limit the effects of LAM treatment. LAM therapy is effective in suppressing HBV replication to undetectable levels by PCR, in relieving liver disease and in achieving HBsAg seroconversion (25). The rate of YMDD mutations in patients after one year of LAM therapy was $14-32 \%(7,8,10,16,20)$. However, the rate of
YMDD mutation after one year LAM therapy of the present study was $12.12 \%$, which is slightly lower than a previous study (15). Allen (8) classified YMDD mutations into two categories: rtM204V + rtL180M and rtM204I, and the study suggested that rtM204V and rtL180M do not occur alone. rtM204I + rtL180M was identified in a study by Lok et al (26) Kobayashi et al (27) detected YMDD mutations in HBV asymptomatic carriers who did not receive LAM therapy. Furthermore, the YMDD mutation was detected in patients with chronic hepatitis B that underwent pre-therapy with LAM $(28,29)$, which differs from the previous conclusion that LAM therapy induced YMDD mutations (30). In the present study, no YMDD mutations were detected at baseline and after 6 months of LAM therapy, while two common types of mutations: rtM204V + rtL180M (2 cases) and rtL180M alone ( 2 cases) were identified after 12 months LAM therapy, and no rtM204I was found. However, other types of mutations including rtV207 L, rtC188S, rtP177R, rtS176R, rtV173 L, rtG172R, rtH160Q, rtF151Y and rtL145 M were detected, whose characteristics are require further study.

As observed in previous studies, the mutations are commonly found among patients with genotype $\mathrm{C}$, which is prevalent in East Asia and associated with more advanced liver disease $(5,31)$. However, the overall incidence rate of rtM204I mutation in genotype B $(45.61 \%, 26 / 57)$ was more frequent compared with genotype $\mathrm{C}(20.59 \%, 7 / 34 ; \mathrm{P}<0.05)$, even if the incidence rate of other mutation patterns did not differ significantly between genotypes B and C (19). In addition, a review analysis of 29 studies reported that 827 patients with a known hepatitis B genotype who underwent LAM treatment and developed resistance mutations (32). The present data revealed that genotype A is associated with the rtM204V, unlike the other major genotypes $(\mathrm{P}<0.001)$, and corresponds to a significant difference in the mutation pattern of genotypes endemic in Asian populations. Furthermore, the rtL180M mutation is significantly associated with the rtM204V in genotypes A, $\mathrm{B}$ and $\mathrm{C}$ (18). The above studies show that HBV genotypes differ in their mutation pattern. In the present study, two rtM204V mutations were detected in genotype C, and a total of four rtL180M mutations appeared, three in genotype C, and one in genotype D. The present findings also suggest that these mutations are commonly found among patients with genotype $\mathrm{C}$.

It has previously been demonstrated in clinical studies of LAM therapy that drug resistance may appear following YMDD mutation (33). The YMDD motif is the binding site of LAM $(8,9)$; thus, the occurrence of YMDD mutations may affect LAM binding with the YMDD motif. In the present study, the possible mechanism underlying this process was investigated by analyzing the secondary structure of YMDD mutations. The secondary protein structure was analyzed prior to and following the occurrence of rtM204V + rtL180M. When the mutation appeared, although the $\beta$ turn corresponding to rtL180M did not change, the $\beta$ turn corresponding to rtM204V changed to $\beta$ sheet. Thus, the change in secondary protein structure may affect the three-dimensional structure of the protein, then affect the combination of LAM with the protein and lead to drug resistance. However, in the present study, drug resistance only appeared in one of the two patients with rtM204V + rtL180M. Recently, one report has demonstrated 
that therapeutic effects continue to be associated with LAM therapy, even after emergence of YMDD mutations (28). It remains unclear why no drug resistance developed in the other patient with the same mutations. LAM remains a viable antiviral therapy for $\mathrm{HBeAg}$ negative patients with chronic hepatitis B. The rates of maintained virological and biochemical responses to LAM decrease in time due to the selection of drug-resistant mutants, leading to viral survival and duplication (25). The potential mechanism underlying this process requires further study.

In conclusion, the study present study performed in patients from Shenyang (China) indicated that there were no significant differences among the genotypes in terms of improvement of ALT normalization, HBeAg seroconversion, $\mathrm{HBeAg}$ loss and HBV DNA loss following one year of LAM treatment. YMDD mutations induced by LAM therapy appeared after 6 months of treatment, and the rate of YMDD mutations in patients after one year of LAM therapy was $12.12 \%$. Two common types of mutation were detected: $\mathrm{rtM} 204 \mathrm{~V}+\mathrm{rtL} 180 \mathrm{M}$ and $\mathrm{rtL180M}$ alone. The mutations were also commonly found among patients with genotype $C$. The $\beta$ turn changed to $\beta$ sheet following the occurrence of the rtM204V mutation. This may be the mechanism underlying LAM resistance. Further large-scale population studies are required to elucidate the mechanism underlying LAM resistance with YMDD mutations induced by LAM therapy.

\section{Acknowledgements}

This study was supported by the National Nature Science Foundation of China (grant no. 81200834), Natural Science Foundation of Liaoning Province (grant no. 2013021070) and Shenyang Science and Technology Program (grant no. F10-205-1-10). In addition, this study was supported by China National Fund of Ministry of Science and Technology (grant no. 30972612), Liaoning Provincial Fund of Provincial Department of Science and Technology (grant no. 2009225010-7), Liaoning Provincial Science and Technology plan Projects (grant no. 2011225020), Shenyang Science and Technology Plan Program (grant no.F10-149-9-56) and the Natural Science Foundation of Liaoning Province (grant no. 201202283).

\section{References}

1. Ghaziani T, Sendi H, Shahraz S, Zamor P and Bonkovsky HL: Hepatitis B and liver transplantation: Molecular and clinical features that influence recurrence and outcome. World J Gastroenterol 20: 14142-14155, 2014.

2. Lai CL, Ratziu V, Yuen MF and Poynard T: Viral hepatitis B. Lancet 362: 2089-2094, 2003.

3. Niederau C, Heintges T, Lange S, Goldmann G, Niederau CM, Mohr L and Häussinger D: Long-term follow-up of $\mathrm{HBeAg}$-positive patients treated with interferon alfa for chronic hepatitis B. N Engl J Med 334: 1422-1427, 1996.

4. Lavanchy D: Hepatitis B virus epidemiology, disease burden, treatment and current and emerging prevention and control measures. J Viral Hepat 11: 97-107, 2004

5. Enomoto M, Tamori A, Kohmoto MT, Morikawa H, Habu D, Sakaguchi H, Takeda T, Seki S, Kawada N, Shiomi S and Nishiguchi S: Mutational patterns of hepatitis B virus genome and clinical outcomes after emergence of drug-resistant variants during lamivudine therapy: Analyses of the polymerase gene and full-length sequences. J Med Virol 79: 1664-1670, 2007.
6. França PH, Coelho HS, Brandão CE, Segadas JA, Quintaes RF, Carrilho FJ, Ono-Nita S, Mattos AA, Tovo C, Gouvea VS, et al: The emergence of YMDD mutants precedes biochemical flare by 19 weeks in lamivudine-treated chronic hepatitis B patients: An opportunity for therapy reevaluation. J Med Biol Res 40: 1605-1614, 2007.

7. Yen YH, Lu SN, Chen $\mathrm{CH}$, Wang JH, Wu CM, Hung $\mathrm{CH}$, Tseng PL, Hu TH, Changchien CS and Lee CM: Changes in serum hepatitis $\mathrm{B}$ e antigen ( $\mathrm{HBeAg}$ ) levels associated with the emergence of YMDD mutants in $\mathrm{HBeAg}$ non-seroconverted patients during lamivudine therapy. Liver Int 27: 1349-1355, 2007.

8. Allen MI, Deslauriers M, Andrews CW, Tipples GA, Walters KA, Tyrrell DL, Brown $\mathrm{N}$ and Condreay LD: Identification and characterization of mutations in hepatitis B virus resistant to lamivudine. Lamivudine clinical investigation group. Hepatology 27: 1670-1677, 1998.

9. Seta T, Yokosuka O, Imazeki F, Tagawa $M$ and Saisho $H$ : Emergence of YMDD motif mutants of hepatitis B virus during lamivudine treatment of immunocompetent type B hepatitis patients. J Med Virol 60: 8-16, 2000.

10. Lai CL, Chien RN, Leung NW, Chang TT, Guan R, Tai DI, $\mathrm{Ng} \mathrm{KY,} \mathrm{Wu} \mathrm{PC,} \mathrm{Dent} \mathrm{JC,} \mathrm{Barber} \mathrm{J,} \mathrm{et} \mathrm{al:} \mathrm{A} \mathrm{one-year} \mathrm{trial} \mathrm{of} \mathrm{lami-}$ vudine for chronic hepatitis B. Asia hepatitis lamivudine study group. N Engl J Med 339: 61-68, 1998.

11. Song BC, Suh DJ, Lee HC, Chung YH and Lee YS: Hepatitis B e antigen seroconversion after lamivudine therapy is not durable in patients with chronic hepatitis B in Korea. Hepatology 32: 803-806, 2000.

12. Dienstag JL, Cianciara J, Karayalcin S, Kowdley KV, Willems B, Plisek S, Woessner M, Gardner S and Schiff E: Durability of serologic response after lamivudine treatment of chronic hepatitis B. Hepatology 37: 748-755, 2003.

13. Ito K, Tanaka Y, Orito E, Hirashima N, Ide T, Hino T, Kumashiro R, Kato A, Nukaya H, Sakakibara K, et al: Predicting relapse after cessation of Lamivudine monotherapy for chronic hepatitis B virus infection. Clin Infect Dis 38: 490-495, 2004.

14. Menéndez-Arias L, Álvarez $M$ and Pacheco B: Nucleoside/nucleotide analog inhibitors of hepatitis B virus polymerase: Mechanism of action and resistance. Curr Opin Virol 8: 1-9, 2014.

15. Huang ZM, Huang QW, Qin YQ, He YZ, Qin HJ, Zhou YN, $\mathrm{Xu} \mathrm{X}$ and Huang MJ: YMDD mutations in patients with chronic hepatitis B untreated with antiviral medicines. World J Gastroenterol 11: 867-870, 2005.

16. Ma Y, Ding Y, Juan F and Dou XG: Genotyping the hepatitis B virus with a fragment of the HBV DNA polymerase gene in Shenyang, China. Virol J 8: 315, 2011.

17. Palumbo E: Hepatitis $B$ genotypes and response to antiviral therapy: A review. Am J Ther 14: 306-309, 2007.

18. Damerow H, Yuen L, Wiegand J, Walker C, Bock CT, Locarnini S and Tillmann HL: Mutation pattern of lamivudine resistance in relation to hepatitis B genotypes: Hepatitis B genotypes differ in their lamivudine resistance associated mutation pattern. J Med Virol 82: 1850-1858, 2010.

19. Li SY, Qin L, Zhang L, Song XB, Zhou Y, Zhou J, Lu XJ, Cao J, Wang LL, Wang J and Ying BW: Molecular epidemical characteristics of Lamivudine resistance mutations of HBV in southern China. Med Sci Monit 17: PH75-PH80, 2011.

20. Schalm SW, Heathcote J, Cianciara J, Farrell G, Sherman M, Willems B, Dhillon A, Moorat A, Barber J and Gray DF: Lamivudine and alpha interferon combination treatment of patients with chronic hepatitis B infection: A randomised trial. Gut 46: 562-568, 2000.

21. Dienstag JL, Schiff ER, Wright TL, Perrillo RP, Hann HW, Goodman Z, Crowther L, Condreay LD, Woessner M, Rubin M and Brown NA: Lamivudine as initial treatment for chronic hepatitis B in the United States. N Engl J Med 341: 1256-1263, 1999.

22. Chien RN, Liaw YF and Atkins M: Lamivudine as initial treatment for chronic hepatitis B in the United States. Hepatology 30: 770-774, 1999.

23. Kim IH, Lee S, Kim SH, Kim SW, Lee SO, Lee ST, Kim DG, Choi CS and Kim HC: Treatment outcomes of clevudine versus lamivudine at week 48 in naïve patients with $\mathrm{HBeAg}$ positive chronic hepatitis B. J Korean Med Sci 25: 738-745, 2010.

24. Bae SH, Baek YH, Lee SW and Han SY: Treatment efficacy of clevudine, entecavir and lamivudine in treatment-naive patients with $\mathrm{HBeAg}$-positive chronic hepatitis B. Korean J Gastroenterol 56: 365-372, 2010 (In Korean). 
25. Ismail S, Hafez HA, Darweesh SK, Kamal KH and Esmat G: Virologic response and breakthrough in chronic hepatitis $B$ Egyptian patients receiving lamivudine therapy. Ann Gastroenterol 27: 380-386, 2014.

26. Lok AS, Hussain M, Cursano C, Margotti M, Gramenzi A, Grazi GL, Jovine E, Benardi M and Andreone P: Evolution of hepatitis B virus polymerase gene mutations in hepatitis B e antigen-negative patients receiving lamivudine therapy. Hepatology 32: 1145-1153, 2000

27. Kobayashi S, Ide T and Sata M: Detection of YMDD motif mutations in some lamivudine-untreated asymptomatic hepatitis B virus carriers. J Hepatol 34: 584-586, 2001.

28. Lee SH, Kim HS, Byun IS, Jeong SW, Kim SG, Jang JY, Kim YS and Kim BS: Pre-existing YMDD mutants in treatment-naïve patients with chronic hepatitis B are not selected during lamivudine therapy. J Med Virol 84: 217-222, 2012.

29. Tan Y, Ding K, Su J, Trinh X, Peng Z, Gong Y, Chen L, Cui Q Lei $N$, Chen $X$ and $Y u$ R: The naturally occurring YMDD mutation among patients chronically infected HBV and untreated with lamivudine: A systematic review and meta-analysis. PLoS One 7: e32789, 2012.
30. Rahimi R, Hosseini SY, Fattahi MR, Sepehrimanesh M, Safarpour A, Malekhosseini SA, Nejabat M, Khodadad M and Ardebili M. YMDD motif mutation profile among patients receiving liver transplant due to hepatitis $B$ virus infection with long term lamivudine/immunoglobulin therapy. Hepat Mon 15: e27120, 2015.

31. Orito E, Mizokami M, Sakugawa H, Michitaka K, Ishikawa K, Ichida T, Okanoue T, Yotsuyanagi $\mathrm{H}$ and Iino S: A case-control study for clinical and molecular biological differences between hepatitis B viruses of genotypes B and C. Japan HBV Genotype Research Group. Hepatology 33: 218-223, 2001.

32. Damerow H, Yuen L, Wiegand J, Walker C, Bock CT, Locarnini S and Tillmann HL. Mutation pattern of lamivudine resistance in relation to hepatitis B genotypes: Hepatitis B genotypes differ in their lamivudine resistance associated mutation pattern. J Med Virol 82: 1850-1858, 2010.

33. Xu G, You Q, Pickerill S, Zhong H, Wang H, Shi J, Luo Y, You P, Kong H, Lu F and Hu L: Application of PCR-LDR-nucleic acid detection strip in detection of YMDD mutation in hepatitis B patients treated with lamivudine. J Med Virol 82: 1143-1149, 2010. 